\title{
KEMAMPUAN PERAWAT DALAM PELAKSANAAN SASARAN KESELAMATAN PASIEN
}

\author{
Ade Sulistya Lubis/181101121 \\ adesulistyalubis@gmail.com
}

\begin{abstract}
ABSTRAK
Latar belakang: Keselamatan pasien merupakan tanggung jawab semua perawat, namun masih didapatkan adanya insiden keselamatan pasien yang dilakukan oleh perawat pelaksana. Tujuan: Untuk mengetahui kemampuan perawat dalam pelaksanaan sasaran keselamatan pasien Metode: Jurnal ini menggunakan metode tersearch dan analisis dari berbagai sumber seperti buku teks, buku referensi jurnal, e-book, dan juga membandingkan beberapa jurnal yang berhubungan dengan kemampuan perawat dalam pelaksanaan sasaran keselamatan pasien. Hasil: sasaran keselamatan pasien adalah mendorong perbaikan spesifik dalam keselamatan pasien yang menyoroti bidangbidang bermasalah dalam perawatan kesehatan, memberikan bukti dan solusi hasil konsensus yang berdasarkan nasihat para pakar. Kesimpulan: Sasaran Keselamatan Pasien sangat diutamakan untuk menjamin keselamatan pasien.
\end{abstract}

Kata kunci: Perawat, Sasaran, Keselamatan Pasien.

Background: Patient safety is the responsibility of all nurses, but patient safety incidents still occur by implementing nurses. Objective: To find out the nurse's ability in implementing patient safety goals. Method: This journal uses the search method and analysis from various sources such as textbooks, journal reference books, e-books, and also compares several journals related to nurses' ability in implementing patient safety goals . Results: the goal of patient safety is to encourage specific improvements in patient safety that highlight problem areas in health care, provide evidence and consensus outcome solutions based on expert advice. Conclusion: Patient Safety Goals are highly prioritized to ensure patient safety.

Keywords: Nurse, Target, Patient Safety. 


\section{LATAR BELAKANG}

\section{PENDAHULUAN}

Sasaran Keselamatan Pasien adalah mendorong peningkatan spesifik dalam keselamatan pasien. Sasaran ini menyoroti area yang bermasalah dalam pelayanan kesehatan dan menguraikan tentang solusi atas konsensus berbasis bukti dan keahlian terhadap permasalahan ini. Patient Safety adalah suatu sistem yang mencegah terjadinya Kejadian Tidak Diharapkan (KTD) akibat tindakan yang dilakukan atau bahkan tidak dilakukan oleh tenaga medis maupun non medis. Sistem tersebut meliputi: assessmen resiko, identifikasi dan pengelolaan hal yang berhubungan dengan risiko pasien, pelaporan dan analisis insiden, kemampuan belajar dari insiden dan tindak lanjutnya serta implementasi solusi untuk meminimalkan timbulnya resiko (Depkes, 2008).

Perawat sebagai tenaga kesehatan yang jumlahnya terbesar di rumah sakit (sebesar 40-60 \%) memiliki jobdesk yang dituntut untuk selalu menerapkan 6 Sasaran Keselamatan Pasien sehingga memiliki peran kunci dalam menentukan keberhasilan akreditasi JCI tingkat paripurna. Sikap perawat dalam mendukung penerapan 6 Sasaran Keselamatan Pasien sangat diutamakan untuk menjamin keselamatan pasien. Asuhan keperawatan memiliki peran yang sangat penting dalam mencegah KTD yang terjadi pada pasien dan lingkungan keperawatan. Jasa perawat dibutuhkan selama 24 jam oleh pasien sehingga memiliki waktu kontak paling banyak dibanding tenaga kesehatan lain untuk berhubungan dengan pasien.

\section{TUJUAN}

Tujuan pembandigan dari beberapa jurnal dan sumber lainnya agar dapat mengetahui kemampuan perawat dalam pelaksanaan sasaran keselamatan pasien. Kemampuan perawat dalam melaksanakan sasaran keselamatan pasien dapat meningkatkan keselamatan pasien.

\section{METODE}

Jurnal ini menggunakan metode tersearch dan analisis dari berbagai sumber seperti buku teks, buku referensi jurnal, e-book, 
dan juga membandingkan beberapa jurnal yang berhubungan dengan kemampuan perawat dalam pelaksanaan sasaran keselamatan pasien. Dari analisi berbagai sumber digunakan untuk mengetahui bagaimana kemampuan perawat dalam pelaksanaan sasaran keselamatan pasien. Penulisan jurnal ini dimulai pada tanggal 02 oktober 2019. Pengolahan jurnal dilakukan dengan metode membandingkan beberapa jurnal yang berhubungan kemampuan perawat dalam pelaksanaan sasaran keselamatan pasien.

\section{HASIL}

Dari hasil jurnal (Reno Afriza Ner, dkk. analisis pelaksanaan sasaran keselamatan pasien di rawat inap rumah sakit umum daerah padang pariaman: Jurnal Kesehatan Andalas. 2018; 7(Supplement 4)) World Health Organization (WHO) menyatakan keselamatan pasien merupakan masalah kesehatan masyarakat global yang serius. Kesalahan medis dapat disebabkan oleh faktor sistem dan faktor manusia. Insiden keselamatan pasien yang merugikan adalah terkait dengan prosedur bedah
(27\%), kesalahan pengobatan $(18,3 \%)$ dan kesehatan infeksi terkait perawatan $(12,2 \%)$ (WHO, 2017). Sedangkan di Eropa, kejadian pasien dengan risiko infeksi sebanyak $83,5 \%$ dan bukti kesalahan medis menunjukkan 50- 72,3\%.

Setiap rumah sakit wajib mengupayakan pemenuhan sasaran keselamatan pasien. Hal ini telah diatur dalam Peraturan Menteri Kesehatan (Permenkes) nomor 11 tahun 2017. Penyusunan sasaran ini mengacu pada Nine Life-Saving Patient Safety Solutions dari World Health Organization (WHO), yang juga digunakan oleh Komite Keselamatan Pasien Rumah Sakit (KKP-RS) dan Joint Commisions International (JCI).

Sasaran keselamatan pasien meliputi tercapainya hal-hal sebagai berikut: 1) ketepatan identifikasi pasien; 2) peningkatan komunikasi yang efektif; 3) peningkatan keamanan obat-obatan yang harus diwaspadai; 4) kepastian lokasi pembedahan yang benar, prosedur yang benar dan pembedahan pada pasien yang benar; 5) pengurangan risiko infeksi terkait pelayanan kesehatan; 6) pengurangan risiko cedera pasien akibat terjatuh. Maksud dari sasaran keselamatan 
pasien adalah mendorong perbaikan spesifik dalam keselamatan pasien yang menyoroti bidang-bidang bermasalah dalam perawatan kesehatan, memberikan bukti dan solusi hasil konsensus yang berdasarkan nasihat para pakar.

\section{PEMBAHASAN}

Jurnal (Setiyani, M. D. (2016). Implementasi Sasaran Keselamatan Pasien Di Ruang Rawat Inap RSU Kabupaten Tangerang. JKFT, (2), 5969) Sasaran Keselamatan Pasien merupakan syarat untuk diterapkan di semua rumah sakit yang diakreditasi oleh Komisi Akreditasi Rumah Sakit. Penyusunan sasaran ini mengacu kepada Nine Life-Saving Patient Safety Solutions dari WHO (2007) yang digunakan juga oleh Komite Keselamatan Pasien Rumah Sakit (KKPRS PERSI), dan dari Joint Commission International (JCI). Menurut Tim KP-RS RSUP Sanglah Denpasar (2011) terdapat enam sasaran keselamatan pasien yang menjadi prioritas gerakan keselamatan pasien. Enam sasaran keselamatan pasien adalah tercapainya hal-hal sebagai berikut :

\section{a. Sasaran I : Mengidentifikasi} Pasien dengan Tepat

Rumah sakit mengembangkan pendekatan untuk memperbaiki meningkatkan ketelitian dalam mengidentifikasi pasien. Kesalahan dalam mengidentifikasi pasien bisa terjadi pada pasien yang dalam keadaan yang terbius/tersedasi, disorientasi, tidak sadar, bertukar tempat tidur / kamar / lokasi di rumah sakit, adanya kelainan sensori, atau akibat situasi yang lain. Adapun maksud dari sasaran ini adalah untuk melakukan dua kali pengecekan dalam setiap kegiatan pelayanan ke pasien. Pertama untuk identifikasi pasien sebagai individu yang akan menerima pelayanan atau pengobatan dan kedua untuk kesesuaian pelayanan atau pengobatan terhadap individu tersebut. Kebijakan atau prosedur yang dilakukan secara kolaboratif dikembangkan untuk memperbaiki proses identifikasi khususnya pada proses pengidentifikasian pasien ketika pemberian obat, darah, atau 
produk dan spesimen lain untuk pemeriksaan klinis atau pemberian pengobatan serta tindakan lain. Kebijakan atau prosedur tersebut memerlukan sedikitnya dua cara untuk mengidentifikasi seorang pasien seperti nama pasien, nomor rekam medis, tanggal lahir, gelang identitas pasien dengan bar-code, dan lainlain. Suatu proses kolaboratif digunakan untuk mengembangkan kebijakan atau prosedur agar dapat memastikan semua kemungkinan situasi untuk dapat diidentifikasi dengan tepat dan cepat.

\section{b. Sasaran II: Meningkatkan} Komunikasi yang Efektif

Rumah

sakit

mengembangkan pendekatan

untuk meningkatkan komunikasi yang efektif antar para pemberi layanan. Komunikasi yang dilakukan secara efektif, akurat , tepat waktu, lengkap, jelas, dan yang mudah dipahami oleh pasien akan mengurangi kesalahan dan dapat meningkatkan keselamatan pasien. Komunikasi yang mudah menimbulkan kesalahan persepsi kebanyakan terjadi pada saat perintah diberikan secara lisan atau melalui telepon mudah terjadi kesalahan yang lain adalah pelaporan kembali hasil pemeriksaan kritis.

c. Sasaran III: Peningkatan Keamanan Obat yang Membutuhkan Perhatian

Rumah sakit perlu mengembangkan suatu pendekatan untuk memperbaiki keamanan obat-obat yang perlu diwaspadai (high-alert). Bila obat-obatan menjadi bagian dari rencana pengobatan pasien, manajemen rumah sakit harus berperan secara kritis untuk memastikan keselamatan pasien agar terhindar dari risiko kesalahan pemberian obat. Obat-obatan yang perlu diwaspadai (highalert medications) adalah obat yang sering menyebabkan terjadi kesalahan serius (sentinel event), obat yang berisiko tinggi menyebabkan dampak yang tidak diinginkan (adverse outcome) seperti obatobat yang terlihat mirip dan kedengarannya mirip. 
d. Sasaran IV: Mengurangi Risiko Salah Lokasi, Salah Pasien dan Tindakan Operasi

Rumah sakit dapat mengembangkan suatu pendekatan untuk memastikan pemberian pelayanan dilakukan dengan tepat lokasi, tepat-prosedur, dan tepatpasien. Salah lokasi, salah pasien, salah prosedur, pada operasi adalah sesuatu yang menkhawatirkan dan kemungkinan terjadi di rumah sakit. Kesalahan ini merupakan akibat dari komunikasi yang tidak efektif atau yang tidak adekuat antara anggota tim bedah, kurangnya melibatkan pasien di dalam penandaan lokasi (site marking), dan tidak ada prosedur untuk verifikasi lokasi operasi.

e. Sasaran V: Mengurangi Risiko Infeksi

Rumah sakit mengembangkan suatu pendekatan untuk mengurangi risiko infeksi yang terkait pelayanan kesehatan yang diberikan. Pencegahan dan pengendalian infeksi merupakan tantangan terbesar dalam tatanan pelayanan kesehatan dan peningkatan biaya untuk mengatasi infeksi yang berhubungan dengan pelayanan kesehatan merupakan hal yang menjadi perhatian besar bagi pasien maupun para profesional pelayanan kesehatan.

Keselamatan pasien pada pelayanan keperawatan menjadi suatu yang harus diterapkan. Pemberian pelayanan kepada pasien lebih aman selama dalam proses perawatan di rumah sakit. Keselamatan pasien RS dapat dinilai dengan melihat sasaran keselamatan pasien atau yang sering dikenal dengan International Patient Safety Goals (IPSG). Tujuan mendasar keselamatan pasien disusun dalam rangka meningkatkan pelayanan kesehatan yang aman dan bermutu tinggi, selalu menilai peningkatan keselamatan pasien di RS. Sasaran keselamatan pasien dapat dibagi menjadi 6 adalah: Identifitas pasien tepat, Ketepatan berkomunikasi, waspada terhadap obat yang mirip, Ketepatan titik 
operasi, cara serta pasiennya, menurunkan potensial terjadi infeksi dan menghindari pasien terjatuh (PMK RI, 2017). Sasaran keselamatan pasien ini menjadi indikator pelaksanaan pelayanan kesehatan yang bermutu.

\section{f. Sasaran VI: Pengurangan Risiko} Pasien Jatuh

Rumah sakit mengembangkan suatu pendekatan untuk mengurangi risiko pasien dari cedera karena jatuh. Jumlah kasus jatuh cukup bermakna sebagai penyebab cedera bagi pasien rawat inap. Dalam konteks masyarakat yang dilayani, pelayanan yang disediakan, dan fasilitasnya rumah sakit perlu mengevaluasi risiko pasien jatuh dan mengambil tindakan untuk mengurangi risiko cedera bila sampai jatuh.

\section{KESIMPULAN}

Sasaran keselamatan pasien meliputi tercapainya hal-hal sebagai berikut:

1. ketepatan identifikasi pasien;
2. peningkatan komunikasi yang efektif;

3. Peningkatan keamanan obatobatan yang harus diwaspadai;

4. Kepastian lokasi pembedahan yang benar, prosedur yang benar dan pembedahan pada pasien yang benar;

5. pengurangan risiko infeksi terkait pelayanan kesehatan;

6. pengurangan risiko cedera pasien akibat terjatuh.

Pelaksanaan sasaran keselamatan pasien dapat dilihat dari pendekatan sistem, pada komponen input kebijakan dan SPO.

\section{SARAN}

Kemampuan perawat dalam pelaksanaan sasaran keselamatan pasien merupakan tindakan yang harus di perhatikan oleh seorang perawat. Oleh karena itu, setiap rumah sakit di sarankan menerapkan sistem keselamatan pasien dalam rangka meningkatkan pelayanan yang lebih bermutu dan aman serta menjalankan peraturan perundang-undangan yang mewajibkan untuk itu. Agar seluruh komponen sarana pelayanan kesehatan 
bekerja sama dalam upaya mewujudkan patient safety karena upaya keselamatan pasien hanya bisa dicapai dengan baik dengan kerjasama semua pihak.

\section{REFERENSI}

Aprilia, Shelly. (2011). Faktor-faktor yang Mempengaruhi Perawat dalam Penerapan IPSG pada Akreditasi JCI di Instalasi Rawat Inap RS Swasta X Tahun 2011. Skripsi. Program Sarjana Keperawatan Kesehatan Masyarakat Departemen Biostatistik dan Kependudukan. Fakultas Kesehatan Masyarakat. Universitas Indonesia Jakarta

Astuti, Tri Puji. (2013). Analisis Penerapan Manajemen Paisen Safety dalam Rangka Peningkatan Mutu Pelayanan di RS PKU Muhammadiyah Surakarta Tahun 2013. Skripsi. Universitas Muhammadiyah Sukarta

Besral, 2011. Perhitungan Besar Sampel. Departemen Biostatistika
Fakultas Kesehatan Masyarakat Universitas Indonesia.

Kemenkes RI. 2011. Peraturan Menteri Kesehatan Republik Indonesia Nomor1691/MENKES/PER/VI II/2011 tentang Keselamatan Pasien Rumah Sakit. Jakarta: Depkes RI.

Kemenkes RI. 2006. Panduan Nasional Keselamatan Pasien Rumah Sakit (Patient Safety): Utamakan Keselamatan Pasien. Jakarta: Depkes RI.

Kemenkes RI. 2008. Panduan Nasional Keselamatan Pasien Rumah Sakit (Patient Safety): Utamakan Keselamatan Pasien. Jakarta: Depkes RI

Nursalam. (2015). Metodelogi Penelitian Ilmu Keperawatan Pendekatan Praktisi Edisi 3. Jakarta: Salemba Medika

R.H.Simamora (2019). Buku ajar pelaksanaaan indentifikasi pasien. Uwais Inspirasi indonesi R.H. Simamora. (2019). The infiuence of Training handover based SBAR Communication for Improving 
patients safety. Indian journal of public heath research \& Deveopment

R.H. Simamora (2019). Documentation of Patient Identifikasi Into the hectronic system to improve the quality of nursing serviceec International) journal of soenrifio \& technology tesearch.

Simamora, R. H. " Buku Aajar keselamatan pasien melalui timbang terima pasien berbasis komunikasi efektif: SBAR.."(2018).

Setiyani, M. D. (2016). Implementasi Sasaran Keselamatan Pasien Di Ruang Rawat Inap RSU Kabupaten Tangerang. JKFT, (2), 59-69

Tri Herawat, Yennike(2015). Budaya Keselamatan Pasien Di Ruang Rawat Inap Rumah Sakit $\mathrm{X}$ Kabupaten Jember, Jurnal IKESMA Volume 11 Nomor 1 Maret.

Potter, P. A., \& Perry, A. G., (2010). Fundamental of nursing. Buku 1,edisi 7. Jakarta : Salemba Medika.

Potter, P. A., \& Perry, A. G., (2013). Fundamentals of nursing. $\quad\left(8^{\text {th }}\right.$ ed). Elsevier.

Permenkes. Peraturan Menteri Kesehatan: No 11, Tahun 2017. 
